Journal of Agricultural and Environmental Ethics (2007) 20:231-245

DOI $10.1007 / \mathrm{s} 10806-007-9035-\mathrm{z}$

(C) Springer 2007

FRANCK L. B. MEIJBOOM

\title{
TRUST, FOOD, AND HEALTH. QUESTIONS OF TRUST AT THE INTERFACE BETWEEN FOOD AND HEALTH
}

(Accepted July 28, 2006)

\begin{abstract}
The food sector and health sector become more and more intertwined. This raises many possibilities, but also questions. One of them is the question of what the implication is for public trust in food and health issues. In this article, I argue that the products on the interface between food and health entails some serious questions of trust. Trust in food products and medical products is often based upon a long history of rather clear patterns of mutual expectations, yet these expectations are not similar in both sectors. As long as the food sector and health sector remain distinct, these differences will not lead to problems of trust, yet when new products are introduced, like functional foods or personalized dietary advices, trust can be threatened. To prevent this, we need clarity with regard to what we can expect of these new products and of whom to expect what in this situation. This requires not only adequate information on operating procedures, but also a profound debate on responsibilities and the explication and interpretation of moral values and norms.
\end{abstract}

KEY WORDS: functional food, health, personalized dietary advice, trust, trustworthiness

\section{THE IMPORTANCE OF TRUST FOR FOOD AND HEALTH}

Milk that lowers your level of cholesterol, dietary advices based on genetic knowledge, new scientific information on the link between a food product and the occurrence of certain types of cancer. These are only some of the many examples of the trend to use health knowledge in the development of food and vice versa. The food and health sectors become more and more intertwined. This raises many possibilities, but also questions. One of them is the question of what the implication is for public trust in both food and health products.

Trust is widely considered to be crucial for both the food sector (FAO, 2003) and the health sector (O'Neill, 2002). First, both sectors have become so complex that an individual cannot but rely on others. Neither as a consumer nor as a patient is one able to assess all the risks and benefits of a product or treatment personally or to fully control any situation. Consequently, we are all necessarily part of complex webs of trust relationships. 
With regard to health, we already have a very long tradition of relying on experts, like physicians and pharmacists. However, it is also the case that it has been many years since the average consumer was able to fully assess all aspects of food consumption. This situation is not exclusive to food and health, yet the importance of consuming food and good health for our daily life leads us to a second reason of why trust is crucial for both sectors. We value food and health highly. Thus, when we have to trust another with regard to either one, or both of them, we have to entrust something highly personal and valuable. This increases the impact of trust on our daily life considerably. Finally, trust in the food sector and the domain of health is colored by some recent affairs and scandals. For instance, in a press release, the Netherlands State Inspectorate of Health recently warned pharmacists not to rely blindly on computerized medication systems because of some serious medication errors that have been reported. ${ }^{1}$ Although all agents probably want and aim to act in a trustworthy manner, the net result is that the trust of some patients may be harmed. Another example is the MPA scandal: In 2002, an illegal hormonal growth promoter, the synthetic progesterone MPA was found on Dutch pig farms. The scandal showed that some agents within the agri-food sector deliberately abused the reliance and trust of others. These examples are exceptions, but they affect trust in the sector.

Given the importance of trust for food and health, it seems reasonable to state that when food aspects are introduced into the medical sector or vice versa, the need for trust will not change. There are no indications that the introduction of health related food products yields a situation in which consumers no longer need to rely on other stakeholders. However, there are indications that it can have a serious impact on trust. Trust in food and health products is often based upon a long history of clear patterns and routines. One knows what one may expect of another. The complicating factor, however, is that the question of whom to expect what is answered differently in the food sector than with regard to health issues. We expect other things of a pharmacist than of the manager of a supermarket, even though they both sell products that we directly consume. As long as both sectors remain distinct, these differences will not lead to problems of trust. Yet, when a functional food with a real health claim is sold in a supermarket, a reflection on mutual expectations is necessary. In order to elaborate on this claim, I first sketch the current developments at the interface between food and health in three ways. Next, I devote some analysis to what we mean by trust. Based upon these two steps, I illustrate the implications of

\footnotetext{
${ }^{1}$ Press release of August, 19, 2005, http://www.igz.nl/standaard.php?pagid $=427$.
} 
the changing relationship between the food sector and health sector upon the idea of trust.

\section{FOOD AND HEALTH: THE CHANGING RELATIONSHIP}

There are a wide range of products and developments that provide examples of the changing relationship between food and health. These include a specific health enhancing food product and rather broad scientific insights into the link between certain substances and the occurrence of certain ailments fit within this development. Hence, it is helpful to differentiate the development in order to trace its impact on trust. It is possible to distinguish three forms of this development.

First, there is an increasing attention to the "health-diet" interaction. The idea that food habits have a direct influence on one's health is certainly not new, yet, as a result of two factors, the attention paid to this relation is increasing. On the one hand, there is ongoing research that yields new insights regarding the relation between food habits and the increase or decrease of the incidence of varies aliments, such as certain types of cancer and different forms of cardiovascular diseases. These scientific developments have not only resulted in extensive literature on the impact of food habits on health, but also in quite practical dietary advice. The daily recommended $200 \mathrm{~g}$ vegetables and 2 pieces of fruit is a good example of an effective guideline to decrease the risk of these ailments. On the other hand, there is an increased attention to the "health-diet" interaction as a result of the combination of enough safe food in the Western world and the unhealthy food and lifestyle habits of many individuals. This has resulted in the problem of obesity. In spite of the clear and practical general dietary advices, compliance rates are very low $^{2}$ and even if they are followed, they are often combined with all kinds of other unhealthy (food) habits. The "epidemic" character of obesity has alarmed different groups and organizations within society all over the World and has resulted in a strongly increased awareness of the health aspect of food products and dietary patterns (WHO, 2000; Astrup, 2004).

In line with the increased attention to "health-diet" interactions, we can distinguish a second development: the growing market for functional foods. This is not one strictly defined group of products, but is the term for a variety of regular food products that have extra qualities that aim to enhance the consumer's health. This development started in Japan as part of the health care service in relation to the ageing population (Ichikawa, 1994).

\footnotetext{
${ }^{2}$ Approximately 70-80 percent do not comply with this advice (Van Oers, 2002; p. 60, Kreijl et al., 2004).
} 
Currently, it is a worldwide development that is very attractive from a market perspective. In functional foods, two developments converge. First, is the above-mentioned growing attention to "health-diet" interactions. Second, is the development within the food sector of products that have added value and consequently have better profit margins. Since there is enough safe food for everyone (in the Western world), the general policy of the food sector has shifted from increasing production rates to more qualityfocused production (McInerney, 2002; Lang, 1999). The aim is no longer to produce more products, but to search for product innovations that yield products with added value. The link with health is an obvious one from that perspective. The profit margins and sales possibilities of health enhancing products are much more promising than those of bulk goods. This has led to the market introduction of various functional foods and to the planned introduction of an even bigger number. Some of them are only partly related to one's health, for instance performance improving soft drinks. Other functional foods claim to have substantial health-improving effects, like margarines that lower elevated levels of blood cholesterol. The more these food products have health-improving effects the more the distinction between food and medicines becomes clouded. This raises several questions, as we will see later on.

Finally, there is an increasing knowledge of the "gene-diet" interaction. This is a combination of the development mentioned at the start of this section and the research in the field of genomics. It seems to be one of the challenges of current research in nutrigenomics to develop dietary advice that is not merely healthy at a population level, but is tailored to the genetic make-up and particular circumstances of an individual, or of a sub-group within a population ( $c f$. Muller and Kersten, 2003; p. 319). These "personalized diets" or "tailor-made dietary advice" promises to be relevant because of their ability to contribute to the cure of ailments, but also because of their contribution to preventive medicine. The knowledge of the gene-diet interaction enables individuals to reduce a genetically induced increased risk to a certain ailment by following specific dietary advice. With the help of such a diet, one may prevent the emergence of the disease. Even though this development is still in a research phase, some practical spin-offs have already been offered to the public, mainly on the internet. The precise applications for the future are not completely clear at this moment, yet it is still considered as promising both as a part of a public approach to health problems and as a more market-focused development in which companies offer dietary products or advice to particular groups (Meijboom, et al., 2003).

In these three developments, we can recognize that the food sector and health sector are becoming increasingly intertwined. This entails new roles 
and responsibilities for the involved professionals, institutions, and consumers. This has a direct impact on trust. In order to substantiate this claim, I first elaborate on what we mean by trust.

\section{TRUST: POSITIVE EXPECTATIONS}

The concept of trust is too complex to take for granted. We are all familiar with trust. Nevertheless trusting has very different dimensions. Trusting the national public health service is quite different from trusting one's GP. Entrusting the care for your health to someone else is perceived rather differently than entrusting your computer problems to the ICT helpdesk. Nevertheless, we talk about trust in all situations. It is this diversity that Hardin has in mind when he writes, "the notion of trust in the vernacular is often vaguely warm and fuzzy" (1999; p. 429). However, it is possible to say something sensible about trust.

First, in all the above-mentioned situations, trust is a matter of dealing with uncertainty and situations where individuals do not have control. It enables us, for instance, to consume food even when we cannot control its production process, or to use medicines even when we cannot assess their safety. In these cases, we do not deliberately take a risk. Trust is not the result of the assessment of hazard and change that can be approached with a calculator on one's desk. In trusting, one acts "as if" certain possible state of affairs will not occur (Lewis and Weigert, 1985; Giddens, 1991). This does not imply that one no longer runs a risk, but rather, that from the perspective of the trustor, one does not deliberately take a risk (cf. Lagerspetz, 1998). This acting "as if" is not an escape to a make-belief world of certainty. In the case of trust, one acts in spite of uncertainty, since one believes one has good reasons for it. The trustor has certain positive expectations towards the attitude and action of another. Thus, trust is a positive expectation in cases of uncertainty and lack of control. However, we neither have such expectations towards all others nor with regard to all issues.

This shows a second point: Trust is relational; it is often focused on specific agents and is indexed to certain situations or a certain object of trust. We do not trust everybody with everything. Normally we entrust something to others when we consider it as valuable and important, but beyond our control. Both are relevant, (a) if something can be determined by a person, she does not need to trust it. For instance, to find out the origin of vegetables would not ask for trust when one grows one's own vegetables. (b) If one considers something as (completely) irrelevant, there is also no necessity to trust. For instance, when a consumer does not prefer to consume "summer vegetables" all year round, he does not need to entrust the 
safety and quality of lettuce in winter to other agents within the agri-food chain, even though he cannot assess it himself. Furthermore, we do not have positive expectations of all others with regard to a specific object. The answer to the question of whom one trusts, depends also on two elements (Baier, 1994). First, a trustee should be competent. Second, he or she should show good will. Here again, both abilities and character are crucial. It is not an either/or position. If someone certainly will show his good-will and respond on my trust, but is completely incompetent as a physician, I will not trust him regarding my health. The other way around, when some person is one of the world's most famous experts, but he obviously has a rather nasty character, it still is quite unlikely that I will trust him. This is a problem that companies and other market parties are often confronted with. They are considered as having enough expertise to be trusted, but are not seen as trustworthy, since one believes that they will not show any good-will, but will only operate on the basis of their self-interest.

Hence, trust is a positive expectation towards competent and goodwilling others regarding issues one values in cases of uncertainty and lack of control. This leads to the final question: Why does one have such a positive expectation in spite of the uncertainty?

\section{REASONS FOR TRUST}

Uncertainty can paralyze individuals and, in the end, even complete sectors and societies. If one were to perceive consuming food or medicines only from the perspective of all the risks one runs, but that one is unable to assess oneself, consumption would be extremely problematic, if not impossible. However, above I argued that trust is a way to act in spite of this uncertainty and to go beyond this situation of paralysis. This acting in spite of uncertainty is more than closing one's eyes to the risks one runs. We have reasons to expect another to act in a specific way, although we cannot control that person or institution. These reasons are in general based upon (a) a certain level of predictability and/or (b) normative considerations.

In the first case we can speak about anticipatory trust (Sztompka, 1999) or predictive trust (Hollis, 1998). These trust relationships are based upon expectations regarding normal patterns and routines. When clear patterns and routines are available, it is often easier to predict how the trusted person will react and what to expect. This enables us to act even though we are confronted with uncertainty and although we cannot control everything involving others. For instance, if one has bought a product for many years, one will expect that its safety and quality remain unchanged the next time 
one buys the product. Hence this person relies on this pattern even though there is always a risk that this is the first time the product is unsafe.

Additionally, there are situations in which we do not merely expect that another will act in a certain way, but we expect something of another (Hollis, 1998). These expectations are not grounded in actual routines, but are based upon more profound beliefs about the way that the other agent will be motivated, or should be motivated, to act in the expected way. For instance, the presumption that reasonable human beings are essentially selfregarding can be the basis for positive expectations when one is confronted with uncertainty, but assesses that it is in another's interest to act in the expected way. This is not merely expecting that another will act according to his self-interest, but one considers it as an important characteristic of reasonable human beings and one expects it of another to be reasonable. Moreover, expectations can be directly based upon moral beliefs. Sometimes, the trustor believes that another has a duty to react in a certain way and that she is entitled to expect this. For instance, regarding government, I do not only expect that they ensure an adequate clinical trial system in introducing new medicines, I also expect it of them. I believe that they have a moral duty to do so and that I am entitled to expect this. This duty does not just depend on my trust, but helps me in trusting another. However, there are also moral duties that are entailed by the act of trusting another. This is what Løgstrup (1959) and Lagerspetz (1998) call the "tacit demand" of trust. ${ }^{3}$ When one entrusts something to the other, it entails an implicit obligation to respond. For instance, a physician has a general duty to care for her patients. This general moral belief can be enough reason for me to trust her, yet because I entrusted her with my health problem, I consider her to have also a specific obligation towards me in this situation. I expect her not just to take care of the health of patients in general, but also to respond to my specific health problem. The presumption that underlies this is that the vulnerability of the trustor should not be abused by the trustee. For instance, the ignorance and dependence of a consumer can never be a reason to tamper with food safety, not even when no one would ever notice.

These different reasons for the expectations that underlie trust are mixed in practice. It is often a multilayered relation. For instance, when I trust my supermarket with regard to the safety of the food on the shelves, I will mainly expect that they will sell the same quality as normal. However, beneath this level of the "expectation that" are my beliefs as to why they will act in accordance to the normal pattern, e.g., because it is in the interest of

\footnotetext{
${ }^{3}$ Scanlon suggests a similar idea by appealing to the "value of assurance." This value explains why it would be reasonable to reject principles that permit people (in the absence of special justification) not to fulfil the expectations they have deliberately raised in others (1998, p. 302-305).
} 
the company to sell safe food. Moreover, I think that they have a moral obligation as a company to take their responsibility to prevent harm seriously, and as a consequence, they have a moral duty to sell nothing but safe food. Finally, the fact that I, as a consumer, have no option but to buy food and thereby trust others entails a tacit demand that requires a response. As long as my trust in food safety is unproblematic, all the underlying levels will remain implicit and I will only expect that my food is safe. Baier rightly compares trust to an atmosphere: we notice trust as we notice air, "only when it becomes scare or polluted" (1994; p. 98). Hence, when there are problems or scandals or when it is no longer clear what to expect, the other levels become explicit.

\section{A NEW RELATION AND THE IMPACT ON TRUST}

Most trust in food products and health products is currently based upon the predictability of the stakeholders. Routines and patterns are often clear enough to act although one is confronted with uncertainty and lack of personal control. ${ }^{4}$ There are long traditions and relatively clear norms that give consumers clarity on what he can reasonably expect of others when he buys a food or pharmaceutical product. However, we lack such clarity with regard to the developments on the interface between food and health. To discuss the impact this has on trust and what the consequences will be for the involved agents, I follow the structure of the three developments in the relationship between the food sector and the domain of health outlined above.

\subsection{Knowledge on the "Health-Diet" Interaction}

The increasing knowledge of the "health-diet" interaction will have an effect on trust in three ways. First, it can show that, although one is not aware of any risk or uncertainty, there certainly is a health risk. The information entails that the consumer takes the step from ignorance to the awareness of the involved risk. For instance, scientific evidence on the health risks of consuming burned meat can show a consumer that the perceived safety of barbequed meat is mainly based upon ignorance. Hence that consumer has to reflect on whether he considers barbequing important and pleasant enough to under take these health risks. In this example, a consumer can make this deliberation himself, but even then, he has to trust the scientific data and information that form the basis of his evaluation. This trust in

\footnotetext{
${ }^{4}$ It is obvious that this does not hold for trust in biotechnology in food, or trust in the immediate aftermath of serious food scandals.
} 
scientific information is mostly anticipatory trust. Since the information has proved to be reliable many times in the past, it is trusted in this situation again. This shows a second impact. The increasing knowledge sometimes complicates anticipatory trust when scientists do not give a clear message on what is healthy and what is not. For instance, eggs have been "not done" for those with elevated levels of blood cholesterol for many years, while a moderate consumption is now conceived as acceptable ( $\mathrm{Hu}$, et al., 1999). This can result in a situation in which only the object of uncertainty changes instead of trust being established. First, one is uncertain about what is healthy, afterwards one is uncertain about which scientist to trust. This shows the impact on a third level. As a result of the increasing knowledge on the "health-diet" interaction, expectations changes towards those who are involved in providing new information. Since most consumers cannot personally assess the available information, they have to trust scientists, dieticians, physicians, or public health institutions. This implies that the information should not only be scientifically sound, but also reckon with the fact that individual consumers are in a dependent position in which they often cannot but trust the experts, for instance by empowering them in order to use this information. Here we recognize the tacit demand of trust, as has been mentioned above. The fact that only trust in the involved agents turns the newly obtained data into useful information, gives a special responsibility to those agents that have the expertise to provide and assess the information.

\subsection{The Market Introduction of Functional Foods}

Foods that have a special health value next to its nutritional value are hightech products that require trust in the expertise and good-will of a whole range of agents. However, this need for trust is complicated by the level of predictability, the clarity with regard to what we can expect of these products, but also by the vagueness regarding whom we can expect this from.

First, these new products will have an effect on trust, since formulating expectations based upon predictability can become difficult. On the one hand, we lack a clear pattern or routine, especially when new technologies, e.g., biotechnology, are used in order to enhance the health effects of food products. A normal pattern as to how to deal with such technologies in food is unavailable. It takes time before trust based upon routine is achievable. Until that moment, trust can be vulnerable, since it is unclear what to expect of the other party. On the other hand, issues of trust will arise as a result of conflicting patterns. This can be explicated with the example of health claims on the labels of food products. The idea of labels with special information is not new. We have already been used to all kinds of labels and 
claims regarding food products, like "high fat," "low sugar," or "new formula." Regarding pharmaceutical products, we have a similar situation in which the expectations concerning the instructions for use are clear. Yet labels that inform you about the health enhancing aspects of food are new. Consequently, it is not quite clear what to expect of them. We can consider them as the usual food labels and adapt our expectations to what we normally expect of them, or we apply our expectations regarding the instructions for use of pharmaceutical products. This indistinctness can have a direct influence on trust in food and pharmaceutical products. For instance, when a label on a traditional product tells me that it is especially relevant for elderly people, I still think that it is safe and unproblematic to use it even when I do not belong to the target group. In the case of a pharmaceutical product such an indication will alert me. Even when it is prescribed by my GP, I will ask him whether this product is safe and effective for me. Thus, when a (imaginary) dairy product with a special hormone is introduced to the market that has substantial health effects for elderly consumers only, the expectations I can reasonably formulate regarding this product are unclear. In this situation, trust will become problematic, because there is no clear routine that tells me what I can expect of this product. Moreover, it also affects my expectations with regard to other food and pharmaceutical products, since I am no longer sure whether my "normal" expectations still apply to those products. Some of these problems of trust may disappear over time. Just as trust in trains was very low in the $19^{\text {th }}$ Century, one can argue that there will be enough predictability and clear routines in the future to serve as foundation for our trust. However, above we have seen that trust is not merely based upon predictability, but also on social and moral norms. Therefore, trust in food products with health claims is not merely a matter of getting used to a new situation.

Trust also requires clarity on what underlies the existing patterns, i.e., what one reasonably can expect of another in this new situation apart from any routine or pattern. At this point the problem is not the lack of norms, but the conflicts between them. For instance, for both the food sector and health sector, safety is paramount in every introduction of a product. Nevertheless, the specific interpretation of what safety means in relation to pharmaceutical products is different from food products. What we consider as an acceptable safety standard regarding food is considered as insufficient for medicine and we accept side effects of medication that we would never accept in the case of food. These differences are not just the result of different customs, but are the result of reflection on what we consider as a morally acceptable risk, given the aim of the product. This reflection can explain why we will not accept the adverse effects of medication for diabetes from a slice of bread. The aim of treating diabetes is considered to be 
important enough to outweigh these problems, while we lack such an aim in the case of bread. Such reflections - not only on safety, but also concerning other issues like justice and autonomy - are necessary for trust in functional foods.

Finally, functional foods show that the developments at the interface between food and heath provide us with questions of whom we expect what. Traditionally, health improvement has been a matter of physicians, pharmacists, and other health professionals. Currently, other parties - mostly market parties - have started to play an important role in this field as well. Since our expectations are both sector-dependent and agent-relative, this shift has implications for trust. In many cases, we trust not merely someone to do what we trust all others to do, but we require a specific action that we can reasonably expect of that person. However, our expectations differ from stakeholder to stakeholder. What one expects of a supermarket is often completely different from what is expected from a pharmacy. For instance, attention to taste and aesthetics is not something we expect of a pharmaceutical company, yet we trust food companies to pay a lot of attention to taste and design before introducing a new product. Likewise, we do not expect a greengrocer to ask every consumer that buys strawberries whether he or she is allergic to them. For a physician this is quite different. When he knows that some medication can have adverse effects for those who have high blood pressure, we expect her to take account of this fact in prescribing other medication. Normally, these differences are not very problematic as far as it is clear whom one can expect to take care of the issues at stake. However, it becomes more difficult to determine what to expect of whom, if a greengrocer were to sell vegetables claiming real health benefits. The answer to this question is crucial for trust in relation to functional foods.

\subsection{Increasing Knowledge of the "Gene-Diet" Interaction}

The combination of genetic and dietary knowledge that aims to develop dietary advice tailored to one's genes equally raises questions of trust. First, as in the case of the increasing knowledge of the food-health interaction, the genetic knowledge can inform an individual of risks he runs of which he was not aware. Personal diets are a kind of preventive medicine. They focus on genetically induced increased levels of risk for a specific ailment. Hence, in most situations, the involved persons have not noticed this risk at all. They did not consider their health status in terms of trust until the information on genetic risks alerts them. Therefore, the range of situations in which one has to trust others will be extended.

Furthermore, the indications that it is likely that personalized diets become a market instrument (cf. Meyer, 2005) rather than a tool for public 
health promotion, has an impact on one's expectations towards others. Instead of scientists, the medical professionals, patients, and government as the key agents, it seems that industry, scientists, consumers, and government will be the central agents in this field. Although we know what we can expect of these agents in normal situations, it is not clear what can be expected of them in respect of tailor-made, individual diets. Companies that provide such advice offer products that were up until now restricted to the medical sector and offer it in ways that are relatively new in relation to health. For instance, the fact that many tests and much dietary advice is currently offered via the internet presumes not only trust in the product, the company that offers it, but also in the proper functioning of the internet. Hence, even when we know what we can expect of the involved others, we also need to know what can be expected of the internet with regard to issues like the confidentiality of medical information. If I want to obtain the test and the dietary advice, I have to trust that my personal information will not end up in a database of other companies than the one that provides me with my tailor-made diet. However, we do not only need to trust more persons and institutions, we also have to entrust some stakeholders with new objects when the dietary advice will be offered in a market context. Trusting a company to be competent and honorable in respect of the offer of a genetic test is for most of us something new. While there is enough precedence to trust a physician to offer a genetic test, for instance because he will offer it if and only if it is really necessary and beneficial for the patient, it is not clear what we can expect of industry. The market has other interests than merely the interest of the consumers. They have shareholders, profit margins, and competitors that all need attention too. This is not something that makes trust in them impossible, yet when genetic tests and personalized dietary advice are offered directly to customers, it should be clear what these individuals can expect of the company, but also what the company expects of its customers.

\section{INFORMATION AND PUBLIC DEBATE ON REASONABLE EXPECTATIONS}

In this article, I have shown that the combination of food and health not only makes trust an even more crucial condition for consuming products, but also raises some serious questions of trust. It is the case that not only will our need to trust experts grow, but that the combination of two sectors entails that existing patterns of trust are either unavailable or insufficiently clear. Consequently it becomes more difficult to base trust in predictability. This implies that the development of attaching health aspects to food and 
dietary products should go hand in hand with adequate information and enhancing transparency on procedures. It should be clear what standard procedures are followed when functional foods or dietary advices are offered. However, this is not merely a matter of good communication. It suggests an underlying need for clarity as to why these procedures are required, e.g., why safety standards for food products are also applicable in the case of functional foods.

This requires a profound debate to elucidate what can be expected of new products and information, and of whom we can expect something with regard to these products. To state that most health related food products require trust in others is not a remarkable statement, yet to identify these "others" is more difficult. All involved agents will be confronted with the fact that responsibilities will be combined together with the combination of food and health. The current problem of this development is that it is not obvious how responsibilities are, or should be distributed in this context. Market parties, researchers, government, and citizens all have responsibilities, however it is not clear beforehand who is responsible for what and to what extent. For instance, consumers get more and more opportunities to influence their own health status, both because they get more information and because they are provided with more tools. This can be the reason for other parties to expect that individuals are responsible for and entrusted with, at least a part of the care of their health. The question is whether this can reasonably be expected of individuals. That an individual is responsible for his own health is not really open for discussion, but the above-mentioned issues suggest that the reality may often be so complex that it becomes difficult to just leave this to the individual. Thus, it is not immediately clear to what extent other stakeholders can expect the individual to be responsible. Likewise, market parties are expected to reckon with the fact that introducing healthenhancing products is more than just a new product innovation. Products on the interface between food and health entail other expectations than those associated with regular food products. However, can we expect of a company that it lives up to all the expectations we normally have regarding the medical sphere, since they introduced a margarine that lowers one's blood cholesterol? Some will answer this question positively, however, one can also argue that this is beyond what one can reasonably be expected of a market party. This shows the importance of the role government can play. Since both food and health are public goods, government intervention that regulates the field between food and health seems to be justified. This can be helpful with regard to those expectations that remain unanswered. Government, for instance, can establish minimal thresholds on safety, quality, and other preconditions for the production 
and consumption of new products. This at least provides clear standards that hold for all involved parties on which expectations can be based. The danger, however, is that all unsolved problems of expectation will end up at the level of the government. Even if most problems of trust with regard to the food-health relation have a public dimension, government cannot take on all of the responsibilities that other agents are not prepared to accept. If they were to do so, they cannot manage to live up to the expectations and consequently cannot be trustworthy. Thus, even though it seems reasonable to expect that there is clear regulation on issues like safety, health claims, and other issues, government cannot "solve" the issues of trust. This shows the need for a profound debate on responsibilities and the explication and interpretation of moral values and norms. Trust in the field of food and health needs clarity as to what we can reasonably expect of each other. This is not an easy discussion, yet it is a necessity for trust that it can deal with situations of transition. Trust is surely a precondition for utilizing the benefits of the developments at the interface between food and health.

\section{REFERENCES}

Astrup, A. (2004), "Trends in National Obesity Prevalences in the Context of the Current Global Obesity Epidemic." The International Association for the Study of Obesity, Obesity Reviews, 5, pp. 173.

Baier, A. C.. (1994), "Trust and Antitrust," in A. C. Baier (ed.), Moral Prejudices, Essays on Ethics, Cambridge: Harvard UP, pp. 95-129.

FAO (2003), Expert Consultation on Food Safety: Science and Ethics, Rome, 3-5 September 2002. Rome: FAO.

Giddens, A. (1991), Modernity and Self-Identity: Self and Society in the Late Modern Age, Cambridge: Polity Press.

Hardin, R. (1999), "Book Review, Trudy Govier, Social Trust and Human Communities." The Journal of Value Inquiry, 33, pp. 429-433.

Hollis, M. (1998), Trust within Reason, Cambridge: Cambridge UP.

Hu, F. B., M. K. Stampfer, E. B. Rimm, J. E. Manson, A. Ascherio, G. A. Colditz, B. A. Rosner, D. Spiegelman, F. E. Speizer, F. M. Sacks, C. H. Hennekens, and W. C. Willett (1999), "A Prospective Study of Egg Consumption and Risk of Cardiovascular Disease in Men and Women." JAMA, 281 (15), pp. 1387-1394.

Ichikawa, T. (1994), "Functional Foods in Japan," in I. Goldberg (ed.), Functional Foods: Designer Foods, Pharmafoods, Nutraceuticals, New York: Chapman \& Hall, pp. 453-467.

Kreijl, C. F., A. G. A. C. Knaap, M. C. M. Busch, A. H. Havelaar, P. G. N. Kramers, D. Kromhout, F. X. R. van Leeuwen, H. M. J. A. van Leent-Loenen, M. C. Ocké, and H. Verkley (eds.) (2004), Ons eten gemeten, RIVM Rapport 270555007. (Houten: Bohn Stafleu Van Loghum).

Lagerspetz, O. (1998), Trust: The Tacit Demand, Dordrecht: Kluwer Academic Publishers. 
Lang T. (1999), "The Complexities of Globalization: The UK as a Case Study of Tensions within the Food System and the Challenge to Food Policy." Agriculture and Human Values 16, pp. 169-185.

Lewis, J. D. and A. Weigert (1985), “Trust as a Social Reality." Social Force, 63 (4), pp. 967-985.

Løgstrup, K. E. (1959), Die ethische Forderung, Tübingen: Laupp.

McInerney, J. (2002), "The Production of Food: from Quantity to Quality." Proceedings of the Nutrition Society, 61, pp. 273-279.

Meijboom, F. L. B., M. F. Verweij, and F. W. A. Brom (2003), "You Eat What You are. Moral Dimensions of Diets Tailored to One's Genes." Journal of Agricultural and Environmental Ethics, 16 (6), pp. 557-568.

Meyer, G. (2005), "Pharma-Food: Are Tailor-Made, Individual Diets Relevant for Problems of Public Health?" EurSafe News, 7 (1), pp. 1-3.

Müller, M. and S. Kersten (2003), "Nutrigenomics: Goals and Strategies." Nature Reviews Genetics, 4, pp. 315-322.

Oers, J. A. M. van (ed.) (2002), Gezondheid op koers? Volksgezondheid Toekomst Verkenning, RIVM rapport 270551001 (Houten: Bohn Stafleu Van Loghum) (Health on Course? The 2002 Dutch Public Health Status and Forecasts Report). O'Neill, O. (2002), Autonomy and Trust in Bioethics, Cambridge: Cambridge UP. Scanlon, T.M. (1998), What We Owe to Each Other, Cambridge: Belknap.

Sztompka, P. (1999), Trust: a Sociological Theory, Cambridge: Cambridge UP.

WHO (2000), Obesity: Preventing and Managing the Global Epidemic - Report of a WHO Consultation on Obesity, 3-5 June 1997, Technical Report Series, No 894 (Geneva: WHO).

Ethics Institute

Utrecht University

Heidelberglaan 2, Utrecht,

NL-3584 CS, Netherland

E-mail:f.l.b.meijboom@uu.nl 